\title{
Article \\ Biomechanics of Trail Running Performance: Quantification of Spatio-Temporal Parameters by Using Low Cost Sensors in Ecological Conditions
}

\author{
Noé Perrotin ${ }^{1}$, Nicolas Gardan ${ }^{1}{ }^{D}$, Arnaud Lesprillier ${ }^{2}$, Clément Le Goff ${ }^{3}{ }^{\circledR}$, Jean-Marc Seigneur ${ }^{4}$, Ellie Abdi ${ }^{5}$, \\ Borja Sanudo $^{6}$ a and Redha Taiar ${ }^{7, *(\mathbb{D})}$ \\ 1 iNumLab Micado, 04200 Sisteron, France; noe.perrotin@afmicado.com (N.P.); \\ nicolas.gardan@afmicado.com (N.G.) \\ 2 Alpi'motion, 04250 Clamensane, France; alpimotion04@gmail.com \\ 3 PSMS Laboratory—EA 7507, University of Reims Champagne-Ardenne, 51100 Reims, France; \\ clement.le-goff@etudiant.univ-reims.fr \\ 4 Medi@LAB, SdS/G3S, University of Geneva, 1205 Geneva, Switzerland; seigneuj@gmail.com \\ 5 Center of Pedagogy, Montclair State University, Montclair, NJ 07043, USA; abdie@montclair.edu \\ 6 Departamento de Educación Física y Deporte, Universidad de Sevilla, 41013 Seville, Spain; bsancor@us.es \\ 7 MATIM, University of Reims Champagne-Ardenne, 51100 Reims, France \\ * Correspondence: redha.taiar@univ-reims.fr
}

check for

updates

Citation: Perrotin, N.; Gardan, N.; Lesprillier, A.; Le Goff, C.; Seigneur, J.-M.; Abdi, E.; Sanudo, B.; Taiar, R. Biomechanics of Trail Running Performance: Quantification of Spatio-Temporal Parameters by Using Low Cost Sensors in Ecological Conditions. Appl. Sci. 2021, 11, 2093. https://doi.org/10.3390/app11052093

Academic Editor: Mark King

Received: 4 February 2021

Accepted: 23 February 2021

Published: 26 February 2021

Publisher's Note: MDPI stays neutral with regard to jurisdictional claims in published maps and institutional affiliations.

Copyright: (c) 2021 by the authors. Licensee MDPI, Basel, Switzerland. This article is an open access article distributed under the terms and conditions of the Creative Commons Attribution (CC BY) license (https:// creativecommons.org/licenses/by/ $4.0 /)$.

\begin{abstract}
The recent popularity of trail running and the use of portable sensors capable of measuring many performance results have led to the growth of new fields in sports science experimentation. Trail running is a challenging sport; it usually involves running uphill, which is physically demanding and therefore requires adaptation to the running style. The main objectives of this study were initially to use three "low-cost" sensors. These low-cost sensors can be acquired by most sports practitioners or trainers. In the second step, measurements were taken in ecological conditions orderly to expose the runners to a real trail course. Furthermore, to combine the collected data to analyze the most efficient running techniques according to the typology of the terrain were taken, as well on the whole trail circuit of less than $10 \mathrm{~km}$. The three sensors used were (i) a Stryd sensor (Stryd Inc., Boulder, CO, USA) based on an inertial measurement unit (IMU), 6 axes (3-axis gyroscope, 3-axis accelerometer) fixed on the top of the runner's shoe, (ii) a Global Positioning System (GPS) watch and (iii) a heart belt. Twenty-eight trail runners ( 25 men, 3 women: average age $36 \pm 8$ years; height: $175.4 \pm 7.2 \mathrm{~cm}$; weight: $68.7 \pm 8.7 \mathrm{~kg}$ ) of different levels completed in a single race over a $8.5 \mathrm{~km}$ course with $490 \mathrm{~m}$ of positive elevation gain. This was performed with different types of terrain uphill $(\mathrm{UH})$, downhill (DH), and road sections $(\mathrm{R})$ at their competitive race pace. On these sections of the course, cadence (SF), step length (SL), ground contact time (GCT), flight time (FT), vertical oscillation (VO), leg stiffness (Kleg), and power (P) were measured with the Stryd. Heart rate, speed, ascent, and descent speed were measured by the heart rate belt and the GPS watch. This study showed that on a $\leq 10 \mathrm{~km}$ trail course the criteria for obtaining a better time on the loop, determined in the test, was consistency in the effort. In a high percentage of climbs $(>30 \%)$, two running techniques stand out: (i) maintaining a high SF and a short SL and (ii) decreasing the SF but increasing the SL. In addition, it has been shown that in steep ( $>28 \%$ ) and technical descents, the average SF of the runners was higher. This happened when their SL was shorter in lower steep and technically challenging descents.
\end{abstract}

Keywords: spatio-temporal parameters; sensors; trail running; biomechanics

\section{Introduction}

Trail running is a popular sport that was recently recognized by the International Association of Athletics Federations (IAAF) as a new running discipline. The sport hosts its own trail world championships (https: / / itra.run, accessed on 15 October 2020) and its pop- 
ularity has led to the growth of the new field of sport science experimentation. Trail running is difficult because it is generally practiced uphill, which increases the body's energy and muscle needs [1]. Athletes' performance has often been monitored using different results such as maximum oxygen consumption $\left(\mathrm{VO}_{2} \mathrm{max}\right)$ with its fractional component: age percentage of $\mathrm{VO}_{2} \mathrm{max}$, ventilation thresholds, lactate thresholds or running economy [1-9]. Nevertheless, measurements of spatio-temporal parameters (STP) under ecological conditions according to the terrain typology in trail athletes are rare and limited to laboratory exercise tests. This does not allow exposure of participants to multiple internal and external stressors both in terms of exercise and environment $[10,11]$. By its nature, trail running is often associated with more difficult and rougher course topography, long climbs and descents, irregular running surfaces with the presence of stones, roots, etc., and variable environmental conditions (i.e., cold, heat, altitude, snow, and humidity) compared to track or road events. The type of terrain therefore has an influence on the biomechanical and psychological state of the runner and therefore on the overall performance of the athlete during a race [1].

In parallel to this craze for running in the mountains, trail and running enthusiasts have become increasingly interested in portable sensors. They allow them to record the distances they run, their paces, their elevation changes and even to visualize them in real time. This is thanks to the use of a watch with a global positioning signal (GPS). The use of GPS also allows runners to quantify their training loads [12]. An important interest was also focused on the measurement of heart rate via the use of a belt or even via watches with sensors based on photoplethysmography. However, this last technology has not been totally reliable using a set of five sports watches during a trail practice [13]. It is recommended in this article to continue the use of a heart belt connected to a watch or an identical device in order to obtain reliable measurements. The use of these technologies is not limited to the world of sports, they are progressively popular in human health care systems or they can facilitate the diagnosis of diseases. The applications of portable sensors are divided into different categories: biophysical monitoring, biochemical monitoring, and real-time data measurement [14]. When it comes to real-time measurement, this technology can even be used to monitor heart rate and its variability while driving, in order to prevent the risk of cardiac arrest [15].

More recently power sensors have made their appearance during recent years in running races [16]. Present for many years in cycling and widely used for performance evaluation and training they come to be very useful for programming training $[17,18]$.

In this study, the Stryd sensor (Stryd Inc., Boulder, CO, USA) was used. The Stryd running power sensor has existed for several years, and two versions have been marketed. The latest version (Stryd Wind) of this sensor was used here. The sensor is fully functional as soon it comes out of the box and does not require a calibration phase before each output. It is a carbon fiber reinforced pedometer that is attached to the laces of the runner's shoe and weighs $8 \mathrm{~g}$. The possibility exists to use the sensor alone because the activation of the accelerometers present allows the recording of the activity to start when the user starts running. However, it is preferable to connect it to a sports watch or a telephone in order to "control" the start and stop of this activity. The sensor attaches to the lowest point of the shoe's lace zone, as indicated by the manufacturer. Based on an inertial measurement unit (IMU), 6 axes (3-axis gyroscope, 3 -axis accelerometer), the data is provided to quantify power (P), stride frequency (SF), vertical oscillation (VO), leg stiffness (Kleg), pace, distance, and elevation during the race. Several studies were able to show the reliability and validation of the parameters presented above. Speed was shown to be valid and reliable during trail or walking [19]. Concerning P, it was reliably measured on different surfaces at sub-maximal speed [20]. The relationship between $P$ and speed was shown to be linear for speeds ranging from 8 to $20 \mathrm{~km} / \mathrm{h}$ on a treadmill [21]. The GCT and Kleg were validated by a recent study for speeds between $8 \mathrm{~km} / \mathrm{h}$ and $20 \mathrm{~km} / \mathrm{h}$ on an indoor track [22]. 
As explained at the beginning of the introduction, measures of STP variation with respect to terrain variability under ecological conditions have not yet been studied. However, several things have already been demonstrated regarding running STP. The level of the participants influences STP with lower SF and vertical stiffness (Kvert) and longer FT and SL for high performance athletes [16]. VO, SF and SL influence the economy of running on the flat [23]. Kleg, GCT, and SF are more important for high level runners in uphill racing. Conversely FT and SL decrease. These parameters affect the uphill running technique [24] and in downhill running, GCT decreases [25].

The studies cited above show that STP have an influence on performance, but these influences have often been demonstrated under stable conditions, on flat circuits or in the laboratory on a treadmill. Our study is based on the following observations, which are the lack of measurements in the field and the great interest in portable sensors by most practitioners. The main objectives were to (i) measure the variation of STP according to the typology of the terrain (ii) in an ecological condition to expose the participants in a variety of trail paths that they could find in competition and (iii) to use so-called "low-cost" portable sensors already used by a large majority of runners. The combination of the data collected will allow the analysis of which STP are related to the best results according to the typology of the terrain. The objective is to orientate the runners to work on certain parameters of their running technique more than others, in order to obtain better performance on a trail circuit of less than $10 \mathrm{~km}$.

\section{Methodology}

\subsection{Subjects}

A group of 30 runners (27 men, 3 women: average age $36 \pm 8$ years; height: $175.5 \pm 7 \mathrm{~cm}$; mass: $68.9 \pm 9.6 \mathrm{~kg}$ ) of different levels, from amateurs with at least one experience on a timed trail race to national level racers (French mountain running championship) participated in this study (Table 1). All subjects met the inclusion criteria: (a) they were over 18 years of age, (b) they had participated in a trail competition previously, and (c) they have not suffered from any injuries in the last 6 months prior to data collection. The participation was voluntarily therefore, participants could leave the study upon receiving detailed information on the study's objectives and procedures. Athletes signed an informed consent form prior to start the study. The study was conducted in accordance with the Helsinki Declaration on human experimentation stated in compliance with the 1964 Helsinki Declaration and its later amendments. Every participant provided written consent after information was given on the aim, protocol, and methodology of the study. The original study was approved by the Ethical Board of the Micado iNumLab (protocol code MIC_2020_0407_ABM and date of approval of 7 April 2020).

Table 1. Avg \pm SD of the physical characteristics of women, men, and all participants.

\begin{tabular}{cccc}
\hline Variables & Females $(\mathbf{n}=\mathbf{3})$ & Males $(\mathbf{n}=\mathbf{2 7})$ & Global $(\mathbf{n}=\mathbf{3 0})$ \\
\hline Age (years) & $35.3 \pm 8$ & $36.5 \pm 8$ & $36.4 \pm 8$ \\
Height $(\mathrm{cm})$ & $160.0 \pm 2$ & $177.2 \pm 5$ & $175.5 \pm 7$ \\
Body mass $(\mathrm{kg})$ & $48.8 \pm 2$ & $71.0 \pm 7$ & $68.9 \pm 9$ \\
Leg length $(\mathrm{cm})$ & $84.8 \pm 1$ & $93.9 \pm 2$ & $93.0 \pm 3$ \\
\hline
\end{tabular}

\subsection{Procedures}

To collect data for the analysis of the study, a course with $8.5 \mathrm{~km}$ and $490 \mathrm{~m}$ of positive height differences was carried out only once by each participant around the city of Sisteron (mountainous region of France). This was composed of a loop with two ascents (UH). The first (UH1) had an average gradient of $13.3 \%$ (219 m D+) over $1.66 \mathrm{~km}$ on a forest road, without technical difficulty. The second (UH2) had an average gradient of $46.1 \%$ (161 m $\mathrm{D}+$ ) on a single track of $384 \mathrm{~m}$, also without technical difficulty. Each loop included two descents (DH). The first descent (DH1) of $400 \mathrm{~m}$ had an average gradient percentage of $28.6 \%$ on a technical track with the presence of stones and roots. The last descent of $1.66 \mathrm{~km}$ 
(DH2) was relatively non-technical with an average gradient of $13.3 \%$. A section on road (R) was also present, with $1 \mathrm{~km}$ and a slightly ascending profile (2.3\%). (Figures 1 and 2).

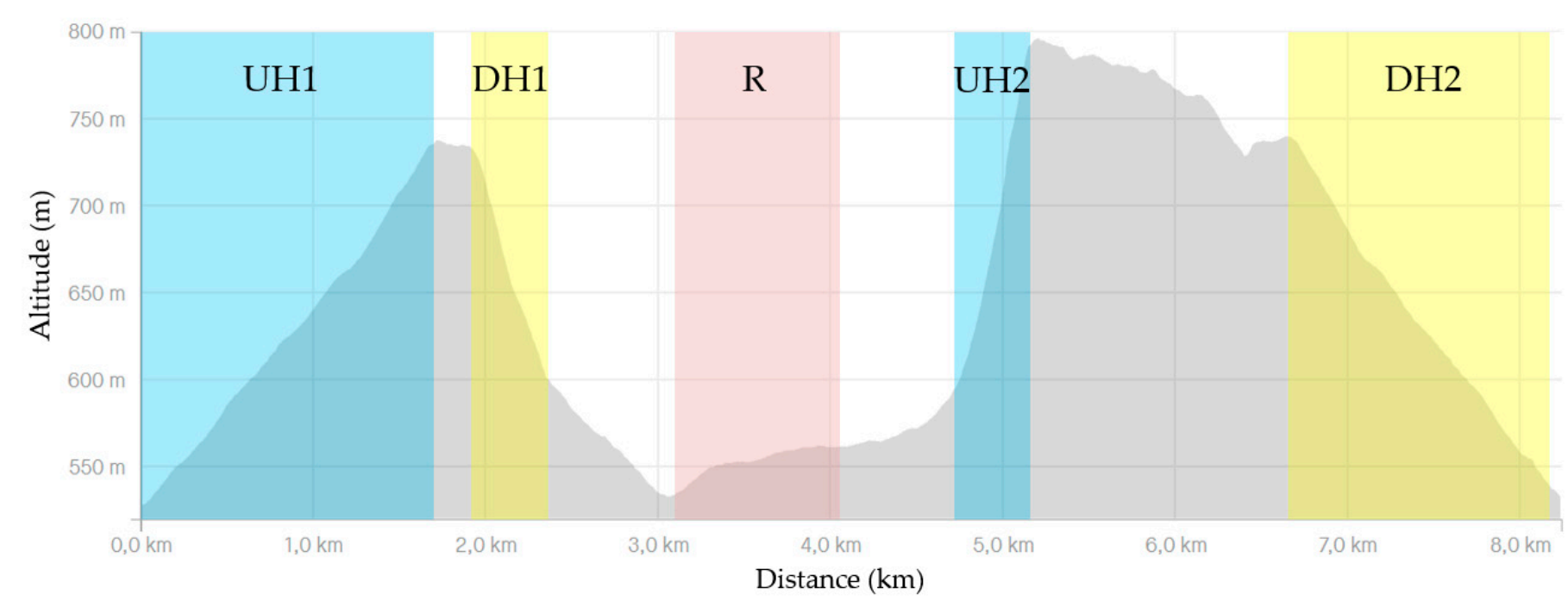

Figure 1. Altimetric profile of the test loop with ascent (UH1), (UH2), descent (DH1), (DH2) and flat (R) sections.

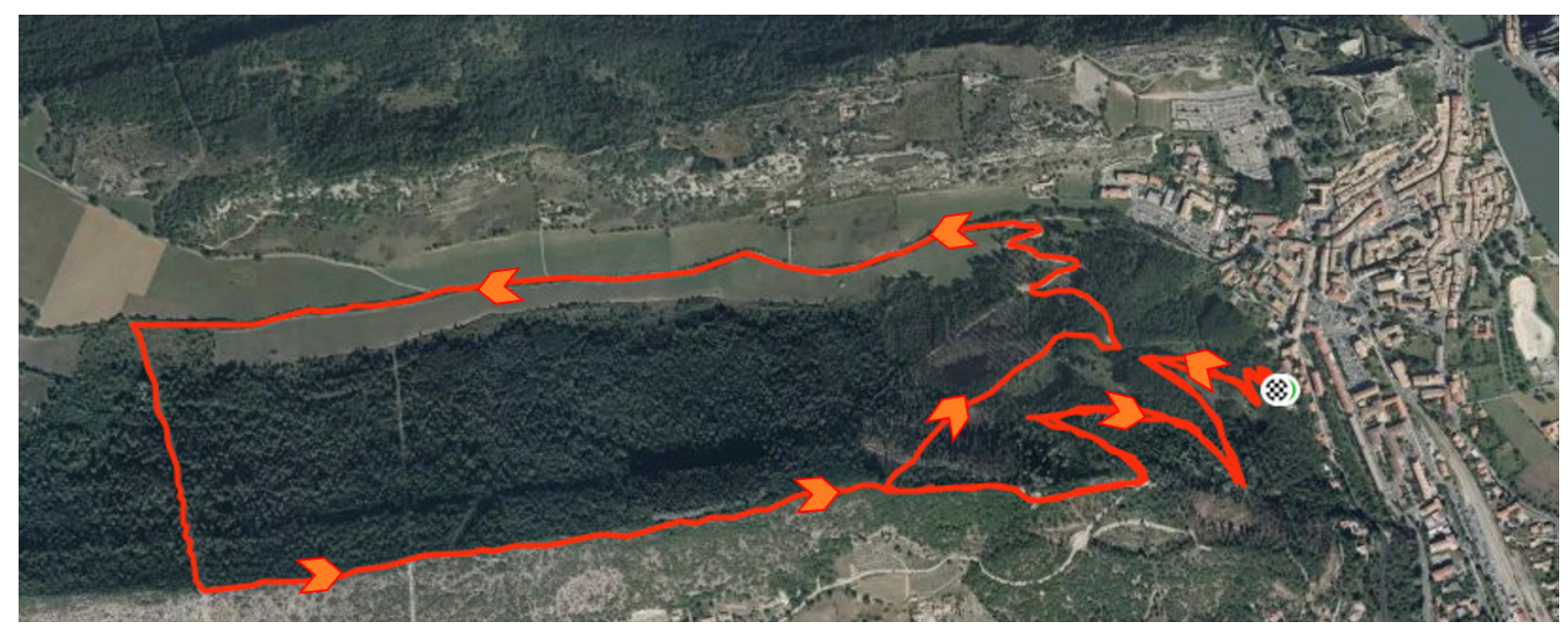

Figure 2. Satellite view of loop.

Visual markers were placed at the beginning and end of each section (i.e., UH1, UH2, $\mathrm{DH} 1, \mathrm{DH} 2$, and R). This was used as indications for the riders thus that they could perform manual laps on the GPS, used for later analysis. The only instruction given to riders before the test was to complete the loop as fast as possible, as if they were in real race conditions. Prior to the start of the test, all subjects had to complete their usual "pre-competitive" warm-up. Depending on the habits of each participant, the warm-up consisted of a slow run on the flat or uphill. Exercise routine, knee lifts and butt heels etc. were also part of the warm-up. Then 2 to 5 accelerations for 20 to 30 s were performed. On average the warm-up "time" was between 5 and 15 min depending on the subjects' preferences.

All subjects wore their own footwear and personal clothing, for the field test, so the test was as close as possible to their frequent running conditions. Previously, subjects were all required to have completed a trail competition to reduce the potential effect of learning on performance [21]. In this study, none of the participants were completed the trail before the testing day. In addition, subjects were required to refrain from physical exercise and alcohol consumption for $24 \mathrm{~h}$ prior to the test to participate in this study. 


\subsection{Mesures}

The spatio-temporal parameters (STP) were recorded at an acquisition frequency of $60 \mathrm{~Hz}$. The Stryd sensor was connected to the Suunto 9 (Suunto, Vaanta, Finland) watch via Bluetooth ${ }^{\circledR}$. Before each test, the mass and height of the runner was entered into the "Stryd" application (version 6.0.1).

The mass of the subject is essential for power calculation. The Stryd uses four parameters which are (1) mass of the subject entered in the application, (2) acceleration, (3) percentage of slope inclination, and (4) speed of the subject obtained with the accelerometers and the gyroscope to estimate the power developed.

The STP that were measured throughout the test included:

- Ground Contact Time (GCT, in seconds): the time between the first moment the foot touches the ground and the last contact of the shoe before the toes lift off the ground.

- $\quad$ Cadence (SF, in steps / $\mathrm{min}$ ): number of times the foot is in contact with the ground per minute.

- Vertical oscillation ( $\mathrm{VO}$, in $\mathrm{cm}$ ): variation in the vertical position of mass' center during the run.

- $\quad$ Leg stiffness $(\mathrm{Kleg}$, in $\mathrm{kN} / \mathrm{m})$ : indicator of a runner's ability to restore the force applied to the ground.

- $\quad$ Flight Time (FT, in seconds): the period between toe-off and the next foot contact. During this phase, the athlete makes no contact with the ground, therefore in essence is in flight. (e.g., right-left).

- $\quad$ Step length (SL, in meters): The distance between the landing of one foot and the next landing of the opposite foot.

- Step time (ST, in seconds): corresponds to the time between the start of the step cycle (placing the foot) and the end of the cycle (placing the same foot again).

Based on previous studies [24] with GCT, SF, ST and running speed, the authors calculated the FT and SL using the following formula:

$$
\begin{aligned}
\mathrm{ST}(\mathrm{s}) & =\frac{60}{\mathrm{SF}\left(\text { step } \cdot \mathrm{min}^{-1}\right)} \\
\mathrm{FT}(\mathrm{s}) & =\mathrm{ST}(\mathrm{s})-\mathrm{GCT}(\mathrm{s}) \\
\mathrm{SL}(\mathrm{m}) & =\frac{\text { velocity }\left(\mathrm{m} \cdot \mathrm{min}^{-1}\right)}{\mathrm{SF}\left(\text { step. } \mathrm{min}^{-1}\right)}
\end{aligned}
$$

- $\quad$ Force $(\mathrm{N})$ : is the mechanical action exerted by one object on another.

- $\quad$ Distance (m): correspond to the length that separates two points.

- Work (J): corresponds to the application of a force $(\mathrm{N})$ over a distance $(\mathrm{m})$.

- Acceleration $\left(\mathrm{m} . \mathrm{s}^{-2}\right)$ : corresponds to a vectorial physical quantity, representing the modification of the speed of a movement as a function of time.

- Velocity $\left(\mathrm{m} . \mathrm{s}^{-1}\right)$ : a variable that measures the ratio of an evolution to time.

Power $(\mathrm{P}$, in $\mathrm{W})$ : the mechanical measurement of the effort and intensity of the run. It corresponds to the work done per unit of time [26].

$$
\text { Power }(\mathrm{W})=\frac{\text { Work }(\mathrm{J})}{\text { Time }(\mathrm{s})}
$$

The work is equal to the force $(\mathrm{N})$ applied multiplied by a distance $(\mathrm{m})$.

$$
\text { Work }(\mathrm{J})=\text { Force }(\mathrm{N}) \text {.Distance }(\mathrm{m})
$$

Therefore, power can be written as:

$$
\text { Power }(\mathrm{W})=\frac{\text { Force }(\mathrm{N}) \text {.Distance }(\mathrm{m})}{\text { Time }(\mathrm{s})}
$$


The distance divided by a time corresponds to velocity, which is more commonly referred to as "speed".

$$
\text { Power }(\mathrm{W})=\text { Force }(\mathrm{N}) \text {.Velocity }\left(\mathrm{m} \cdot \mathrm{s}^{-1}\right)
$$

The force being equal to the mass of an object multiplied by its acceleration, the previous equation can be written as:

$$
\text { Power }(\mathrm{W})=\text { Body masse }(\mathrm{kg}) \cdot \text { Acceleration }\left(\mathrm{m} \cdot \mathrm{s}^{-2}\right) \cdot \operatorname{Velocity}\left(\mathrm{m} \cdot \mathrm{s}^{-1}\right)
$$

Normalized Power (NP, in $\mathrm{W} / \mathrm{Kg})$ : it is the ratio between a power and a mass The heart rate was recorded at an acquisition frequency of $1 \mathrm{~Hz}$.

Average heart rate $(\mathrm{bpm})$ : corresponds to the average heart rate recorded during the test.

The parameters relating to the runner's speed of movement were:

Time ( $\mathrm{min})$ : corresponds to the total time taken by the subject to complete the course. Speed $(\mathrm{km} / \mathrm{h})$ : corresponds to the ratio of a distance traveled over a period.

Pace $(\mathrm{min} / \mathrm{km})$ : corresponds to the ratio of a time over a distance.

Climbing speed $(\mathrm{m} / \mathrm{h})$ : corresponds to the number of meters of positive elevation gain over one hour. Calculated with the following formula [27]:

$$
\text { Climbing speed }(\mathrm{m} / \mathrm{h})=\frac{3600 \times \text { Positive gradient of the ascent }(\mathrm{m})}{\text { Time taken by the subject to complete the climb }(\mathrm{s})}
$$

Descending speed $(\mathrm{m} / \mathrm{h})$ : corresponds to the number of meters of negative difference in level descended over one hour.

$$
\text { Descending speed }(\mathrm{m} / \mathrm{h})=\frac{3600 \times \text { Negative gradient of the downhill }(\mathrm{m})}{\text { Time taken by the subject to complete the downhill }(\mathrm{s})}
$$

\subsection{Materials}

For descriptive purposes, height $(\mathrm{cm})$ and body mass $(\mathrm{kg})$ were determined using a PLR 15 laser pointer with an accuracy of $\pm 3.0 \mathrm{~mm}$ (Bosch Siemens Hausgeräte, Gerlingen, Germany) and a Dara scale (FitTrack, Toronto, Canada) respectively. All measurements were taken with subjects wearing running shorts and underwear. The leg length of the participants was estimated with the following anthropometric equations of Winter (1979) [28], where $h$ is the participant's height (in $\mathrm{m}$ ).

$$
\text { Leg lenght }(\mathrm{m})=0.53 . \mathrm{h}(\mathrm{m})
$$

The STP which are SF, GCT, VO as well as Kleg were measured simultaneously by Stryd (Stryd Inc. Boulder CO, USA). The Stryd (Figure 3) is a carbon fiber reinforced pedometer that is attached to the laces of the shoe and weighs $8 \mathrm{~g}$. A single sensor was attached to the right foot of each participant at the lowest point of the shoe area. Based on an inertial measurement unit (IMU), 6 axes (3-axis gyroscope, 3-axis accelerometer), it provides data to quantify $\mathrm{P}, \mathrm{SF}, \mathrm{VO}, \mathrm{Kleg}$, pace, distance, and elevation during running. Some studies have already examined its validity and reliability for measurement of STP $[16,19,24,29]$. 


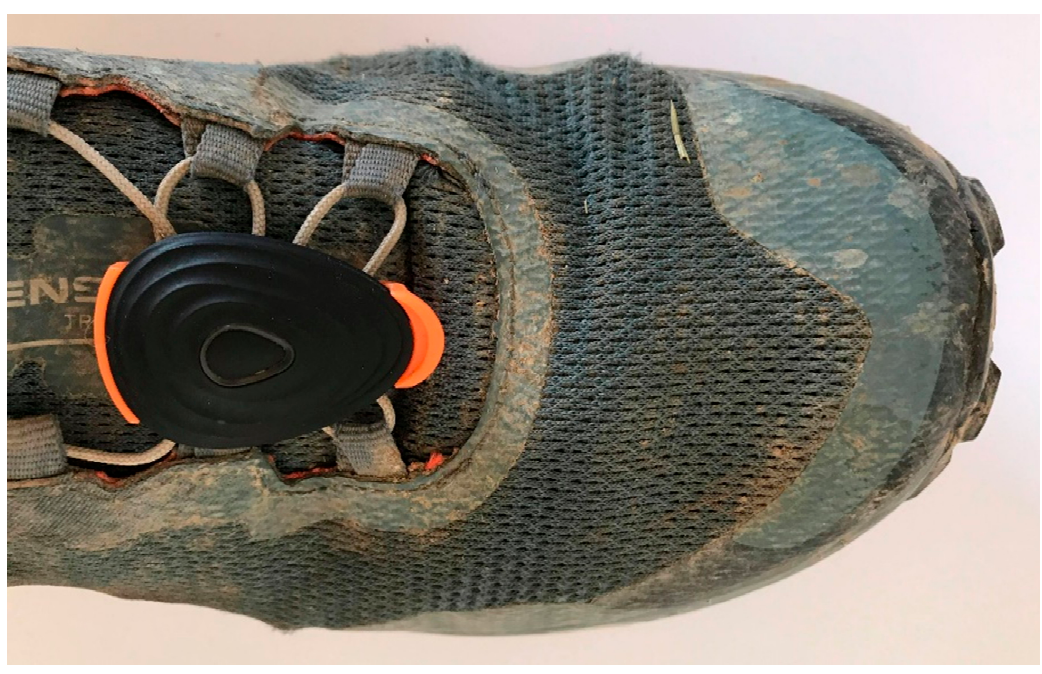

Figure 3. The Stryd sensor fixed on the right shoe of one of the participants.

A Suunto 9 Baro multi-sport GPS watch (Suunto, Vaanta, Finland), using a GPS chip (Sony, Minato-ku, Tokyo, Japan), was used to record information on speed, distance, elevation, and altitude. By GPS watch ascent and descent times were recorded and speeds were calculated. Heart rate in real time using a Suunto "smart sensor" belt was recorded throughout the test.

\subsection{Data Transfert}

Following the field test, the results which were recorded on the watch were downloaded directly to the "Suunto" application (version 1.30.0, Amer sports Digital, Helsinki, Finland). The data was only retrieved relating to time, speed, rate of climb, heart rate, power, and cadence of the test. Subsequently, the Stryd had to be synchronized with the "Stryd" application (version 6.0.1, Athlete Architect LLC, Boulder, CO, USA) via an iPhone 7 (Apple, Cupertino, CA, USA). This allowed the recovery of missing data which were recorded in the Stryd, such as GCT, VO and Kleg. The power center interface of the Stryd.com website was used to synchronize the data from the Suunto application and the data from the Stryd.

\subsection{Statistic Analysis}

Succeeding normalizing the data set, the relationships between the different parameters over the entire route and the different sections were evaluated with Pearson's correlation coefficients. The value of this measure varies from -1 (strong negative correlation) to 1 (strong positive correlation). A value of 0 does not represent a linear correlation. All statistical tests for the parametric analysis were performed on the Knime Analytics platform software (version 4.2.2, Zurich, Switzerland).

\section{Results}

Subjects

The size of the subjects as well as their leg length were negatively correlated with their running stride frequency $(r=-0.72 p<0.001)$ notwithstanding, no relationship was found between subject size and stride length $(r=0.20)$.

Global

The average time over the whole route was $54^{\prime} 4 \mathrm{~min}$ (Table 2). The time of the subjects on the course was correlated with their time on the first ascent UH1 $(\mathrm{r}=0.88 ; p<0.001)$ and their time on the last descent DH2 $(r=0.86 ; p<0.001)$. Significant associations were also found in between the average time and the NP $(r=-0.84 ; p<0.001)$ and SL $(r=-0.90$; $p<0.001)$. 
Table 2. Avg \pm SD values of time, normalized power, stride frequency, ground contact time, flight time, step length, vertical oscillation, and leg stiffness over the entire course and over each defined area of the course.

\begin{tabular}{ccccccccc}
\hline & Time & NP & SF & GCT & FT & SL & VO & Kleg \\
\hline & Min & W/kg & Spm & $M s$ & $M s$ & Cm & Cm & $k N / m$ \\
\hline Global & $54^{\prime} 42 \pm 8^{\prime} 42$ & $3.3 \pm 0.5$ & $154 \pm 11$ & $484 \pm 74$ & $-93 \pm 49$ & $102 \pm 13$ & $5.5 \pm 0.7$ & $8.2 \pm 1.4$ \\
UH1 & $12^{\prime} 18 \pm 2^{\prime} 29$ & $4.1 \pm 0.7$ & $164 \pm 15$ & $334 \pm 125$ & $33 \pm 91$ & $86 \pm 12$ & $5.7 \pm 1.0$ & $9.4 \pm 2.2$ \\
UH2 & $10^{\prime} 57 \pm 2^{\prime} 09$ & $1.9 \pm 0.6$ & $88 \pm 14$ & $1327 \pm 184$ & $-631 \pm 115$ & $41 \pm 5$ & $0.3 \pm 0.7$ & $0.6 \pm 1.4$ \\
R & $5^{\prime} 30 \pm 54^{\prime \prime}$ & $3.9 \pm 0.6$ & $172 \pm 10$ & $252 \pm 32$ & $96 \pm 26$ & $112 \pm 15$ & $7.1 \pm 1.0$ & $9.7 \pm 1.2$ \\
DH1 & $2^{\prime} 09 \pm 36^{\prime \prime}$ & $2.8 \pm 0.8$ & $193 \pm 14$ & $221 \pm 32$ & $90 \pm 23$ & $100 \pm 20$ & $6.1 \pm 1.0$ & $13.9 \pm 2.7$ \\
DH2 & $6^{\prime} 29 \pm 57^{\prime \prime}$ & $3.6 \pm 0.7$ & $174 \pm 12$ & $208 \pm 26$ & $135 \pm 25$ & $145 \pm 19$ & $8.1 \pm 1.3$ & $10.7 \pm 1.4$ \\
\hline
\end{tabular}

(NP) Normalized Power, (SF) Stride frequency, (GCT) Ground contact time, (FT) Fly time, (SL) Stride length, (VO) Vertical oscillation, (Kleg) Leg stiffness, (UH1) first uphill, (UH2) second uphill, (R) road section, (DH1) first downhill, (DH2) second downhill.

The GCT was negatively correlated with the FT $(\mathrm{r}=-0.96 ; p<0.001)$ as well with the $\mathrm{SF}(\mathrm{r}=-0.91 ; p<0.001)$ over the entire route.

Uphill

In the first ascent, the total ascent time was correlated with the GCT $(r=0.81 ; p<0.001)$. The average speed on this climb was correlated with the SL of the subjects. The FT was positively correlated with the runner's SF $(\mathrm{r}=0.69 ; p<0.001)$.

Considering second climb, the total ascent time was negatively correlated with the ascent speed $(\mathrm{r}=-0.97 ; p<0.001)$, the NP $(\mathrm{r}=-0.87 ; p<0.001)$, the SL $(\mathrm{r}=-0.72 ; p<0.001)$ and the SF $(\mathrm{r}=-0.71 ; p<0.001)$ of each runner.

In addition, ascent speed was correlated with NP $(r=0.94 ; p<0.001)$ and SF $(r=0.78$; $p<0.001)$. The same SF was correlated with Kleg $(\mathrm{r}=0.87 ; p<0.001)$ as was the VO which was also correlated with Kleg $(r=0.92 ; p<0.001)$.

The GCT showed a negative correlation with SF $(\mathrm{r}=-0.88 ; p<0.001)$, Kleg $(\mathrm{r}=-0.85$; $p<0.001)$ and $\mathrm{VO}(\mathrm{r}=-0.81 ; p<0.001)$.

Road section

On the road section, the GCT time showed a strong correlation with the total time of the subjects on this section $(\mathrm{r}=0.92 ; p<0.001)$. Conversely, FT showed a negative correlation $(\mathrm{r}=-0.86 ; p<0.001)$, as did SL $(\mathrm{r}=-0.90 ; p<0.001)$. NP $(\mathrm{r}=-0.87 ; p<0.001)$ to the total time spent by the participants on the R.

Downhills

In both descents, it was the GCT that showed a positive correlation with the total descent time with $(\mathrm{r}=0.77 ; p<0.001)$ for DH1 and $(\mathrm{r}=0.90 ; p<0.001)$ for DH2. Conversely, SL showed a negative correlation in both DH1 $(\mathrm{r}=-0.85 ; p<0.001)$ and DH2 $(\mathrm{r}=-0.84$; $p<0.001)$ descents. The same applies to the SF which showed a negative correlation with the VO, DH1 $(\mathrm{r}=0.84 ; p<0.001)$ and DH2 $(\mathrm{r}=-0.86 ; p<0.001)$.

In the first descent, the FT was correlated with SL $(r=0.80 ; p<0.001)$.

In the second descent, the FT was correlated with the VO of the runners $(r=0.82$; $p<0.001)$.

\section{Discussion}

The objective of this study was to quantify STP on a trail course by using low-cost sensors in ecological conditions. The main results suggest that the use of inexpensive sensors (Stryd sensors, GPS watch and heart belt) allow the measurement of STP. These parameters are related to the running technique and the speed of a runner on the whole course or in different sections of the course (UH, DH, R). Following an analysis, these measurements allow the identification of different running strategies for the same type of terrain within a group of runners. However, they also allow a more detailed analysis to identify the different Spt in relation to the performance according to the variation of the terrain.

Firstly, analysis of the physical characteristics of the runners showed that mass of the subjects was positively correlated with their height $(\mathrm{r}=0.80 ; p<0.001)$ and to the length of 
their lower limb $(\mathrm{r}=0.80 ; p<0.001)$. Moreover, larger subjects were shown to have a lower SF than smaller subjects.

Secondly, analysis of the data while looking at the performance of the riders over the entire course displayed that consistency of effort was one of the criteria for obtaining a better time on the loop determined in the test. In fact, the subjects who made a fast UH1 and a DH2 at high speed were those who achieved the best performance. In a study of pace strategies at the World Cross Country Championships, it was shown that the top 10 athletes had a steady race pace, while those who finished lower in the rankings had a fast pace tactic at the beginning of the race which decreased steadily throughout the course [30]. It is possible to suggest that when riders start in a bunch, their effort management changes. This study was a form of time trial which the subjects were alone, therefore it would be interesting to see in a future study if the race management would be different in a group.

The $p$ analysis showed that it is in the UH1 and R part that the most important values are developed by the subjects. This corresponds to sections of the course where the runners had to keep a high speed despite the slope or flatness. In the DH sections the $p$ developed by the subjects is also important even though the runners are on a descending profile. This fact has shown that in the trail, especially in the steep DH but also in the less technical ones where the participant must run fast, the energy demand is high. Above $-20 \%$ of slope, the EC increased during the descent [1]. Runners would have an interest in training downhill as it could be done on the flat or uphill in a fractioned way in order to create potential physical adaptations.

In addition, in the low-percentage climbs $(<13 \%)$ it was the runners who managed to keep a low GCT while taking big steps and passed the difficulty more quickly compared to the other runners. It is with this type of data analysis that the use of handheld sensors can be interesting for a runner who wants to work on the weak points of his or her uphill running technique. Preferentially, a coach who wants to improve the efficiency or a runner's technique in a training group. With a sport watch the visualization of these parameters is in real time. This allows quickly visualizing the changes that would be relevant to modify. In the second climb that had a high percentage of gradient ( $>35 \%)$, it was maintaining a high SF or taking large steps that allowed the runner to pass the difficulty more quickly. We therefore hypothesized that two strategies could be put in place by the runners when the percentage of slope is important. (i) A first strategy would be to decrease SL as well as GCT and increase or maintain SF. (ii) The second strategy would be to increase SL as well GCT, and to decrease SF.

In studies examining the influence of slope ( +2 to $15 \%$ ) on the change in STP, the authors showed that SF increased by 3.9\%, $4.0 \%, 2.9 \%$ and $1.2 \%$ [31-34]. In our study, the average slope was greater than $30 \%$, which does not allow us to make a comparison with the studies cited above. However, one study looked at the variation in FS on a $30 \%$ slope and showed that FS was higher than in the "running flat" condition at the same speed $(16.2 \mathrm{~km} / \mathrm{h})$ [35]. In the present study, in contrast to the above study, subjects ran at an average of $2.2 \mathrm{~km} / \mathrm{h}$ for an average of $11 \mathrm{~min}$. This does not allow us to make a relevant comparison. Therefore, we would need to carry out further measurements in percentages of slopes greater than $30 \%$ in order to confirm or invalidate our hypothesis on the implementation of one of the two running techniques by the runners.

It is possible to assume that runners who would favor the first strategy above would favor the use of their leg muscles (gastrocnemius, soleus, etc.). Subjects using the second strategy more would favor the use of their hamstring muscles (femoral biceps, semitendinosus and semi-membranous) and gluteal muscles (large, medium, and small gluteus).

We were able to observe that on the whole course the SF on the ascent was much lower than the SF on the descent with differences of more than $50 \%$. Compared to the section of road the SF decreased by $26 \%$ in ascent but on the contrary it increased by almost $7 \%$ in descent. These results are consistent with those revealed in the study by Björklund et al. (2019) and Townshend et al. (2010) [25,36]. Indeed, the GCT being negatively correlated 
with the SF throughout the route, this means that the GCT was higher on the uphill side than on the downhill side.

On the road segment, the parameters of GCT and SL showed a correlation with the subjects' performance. Indeed, the runners with the lowest GCT and longest SL ran fastest on the road section. The study by Kyröläinen et al. (2001) found that GCT decreased with increasing running speed in elite middle-distance runners [37]. Garcia-Pinillos et al. (2019) showed a significant increase in SL with increasing speed [38].

We could notice this after the field tests in the first descent which was more technical (percentage of slope $>28 \%$, presence of roots and stones) than the second. The runners had on average a higher SF and a shorter SL. As a result, the technicality of the terrain would lead the runners to take a higher number of steps, but of shorter length. In addition, as indicated in the study by Giandolini et al. (2017) variation in stride could reduce neuromuscular fatigue [39]. It has been shown that the higher SF of the runners, the lower their $\mathrm{VO}$ on the descent. In the first descent with a high percentage of slope, participants increased their SF $(193 \pm 14 \mathrm{ppm})$ while decreasing their SL $(100 \pm 20 \mathrm{~cm})$ and consequently their $\mathrm{VO}(6.1 \pm 1 \mathrm{~cm})$. In the $\mathrm{DH} 2$, which did not present any technical difficulties, the subjects descended faster $(+27 \%)$ with a lower SF $(174 \pm 12 \mathrm{ppm})$, but with longer SL $(145 \pm 19 \mathrm{~cm})$ and therefore a greater $\mathrm{VO}(8.1 \pm 1.3 \mathrm{~cm})$.

The realization of the tests in ecological conditions is a real added value in setting up a study on the trail. It allowed us to expose the runners to different variations and typologies of terrain, which is one of the particularities of mountain running compared to road racing. For this reason, the realization of laboratory tests on a treadmill seems less relevant to study of road running. As we could see in the results of this study, the variations of the terrain force the runners to modify their running technique. In a future study it would be interesting to use sensors that would allow us to recover a set of raw data to identify possible variations in running technique on the same downhill or uphill run.

Moreover, this study showed that the use of portable sensors allowed the collection of a significant amount of information related to the running technique or speed of movement. We thought we could use the heart rate data recorded with the belt during the tests, but this data, although reliable, showed no relationship with performance.

\section{Limitations and Perspectives}

This study has several limitations. The realization of the "laps" on the watch was done by the subjects themselves, therefore it is possible that in an effort and despite the visual cues, there are not the same lengths of measurement sections between each subject. However, during data processing these sections were examined by the operator via Stryd's interface in order to check if the subjects had performed the turns in the right places. As far as the Stryd sensor was concerned, there was no access to the raw data recorded, therefore filters usage is unknown when recording the data. In addition, all accessible data was transcribed as an average and not as a set of values. Hence, it was not possible to observe, for example, the evolution or variation of the cadence during a descent. These data could have provided a significant amount of additional information, perhaps allowing us to arrive at alternative interpretations.

At the time of this study as we did not have electromyography (EMG) sensors to record muscle activity. In a future study, it would be interesting to couple these field measurements with muscle activity values. This will give a chance to researcher an effort to understand more precisely the adaptations of the runners to the typology of the terrain. The use of sensors in the field of sports allows access to a lot of information. Therefore, an even more advanced use in this field could lead researchers to use sets of portable sensors recording all the movements of a runner in the field. This executes retrieve of information on angular velocities, joint loads, etc. To create a digital twin this would be completed with a view to virtualizing it later. Afore mentioned, could be of real interest in the field of sports. To conclude, it is important to specify that this study was totally independent. 


\section{Conclusions}

The results of this study confirmed that it is possible to retrieve relevant data sets for the analysis of the STP one or more runners. This is possible by using "low-cost" sensors under ecological conditions. The measurements taken over the whole course in conjunction with the different sections (UH1, UH2, R, DH1, DH2) were able to show that on a trail course of a distance less than or equal to $10 \mathrm{~km}$, the best running strategy to adopt in order to achieve a better time is the one where the runner will smooth his effort throughout the course. Conversely, starting too fast or too slow at the beginning of the course will be less effective in achieving a better time over the entire course. On climbs with a high percentage $(>30 \%)$, two running techniques stand out, one technique which consists of keeping a high SF but a short SL and another technique which consists of decreasing the SF but taking bigger SL. In technical (presence of roots and stones) and steep $(>20 \%)$ descents, runners increase their SF but decrease their SL. This shows that it is possible for a trail runner or sports coach to use portable sensors (the Stryd and a GPS watch) to self-evaluate or evaluate an athlete in different types of terrain and ecological conditions.

Author Contributions: Data curation, Writing, N.P., N.G.; Methodology, N.P., A.L., and C.L.G.; Supervision, R.T. and B.S., R.T.; review \& editing, E.A. and B.S.; Visualization, J.-M.S. and R.T. All authors have read and agreed to the published version of the manuscript.

Funding: This research received no external funding.

Institutional Review Board Statement: The study was conducted according to the guidelines of the Declaration of Helsinki, and approved by the Ethics Committee of Micado (protocol code MIC_2020_0407_ABM and date of approval of 7 April 2020).

Informed Consent Statement: Informed consent was obtained from all subjects involved in the study. Written informed consent has been obtained from the patient(s) to publish this paper.

Acknowledgments: The authors would like to thank all the participants in this study.

Conflicts of Interest: The authors declare no conflict of interest.

\begin{tabular}{|c|c|}
\hline $\mathrm{DH}$ & Downhill \\
\hline DH1 & First Downhill \\
\hline DH2 & Second Downhill \\
\hline EC & Energy Cost \\
\hline EMG & Electromyography \\
\hline FT & Flight time \\
\hline GCT & Ground Reaction Force \\
\hline GPS & Global Positioning System \\
\hline IAAF & International Association of the Athletics Federations \\
\hline IMU & Inertial measurment unit \\
\hline Kleg & Leg Stiffness \\
\hline Kvert & vertical stiffness \\
\hline NP & Normalized Power \\
\hline $\mathrm{P}$ & Power \\
\hline $\mathrm{R}$ & Road Sections \\
\hline SF & Stride Frequency \\
\hline SL & Stride Length \\
\hline ST & Stride Time \\
\hline STP & Spatio-temporal parameters \\
\hline $\mathrm{UH}$ & Uphill \\
\hline UH1 & First Uphill \\
\hline $\mathrm{UH} 2$ & Second Uphill \\
\hline $\mathrm{VO}$ & Vertical Oscillation \\
\hline $\mathrm{VO}_{2} \mathrm{Max}$ & Maximum Oxygen Consumption \\
\hline
\end{tabular}




\section{References}

1. Vernillo, G.; Giandolini, M.; Edwards, W.B.; Morin, J.-B.; Samozino, P.; Horvais, N.; Millet, G.Y. Biomechanics and Physiology of Uphill and Downhill Running. Sports Med. 2017, 47, 615-629. [CrossRef]

2. Balducci, P.; Clémençon, M.; Trama, R.; Blache, Y.; Hautier, C. Performance Factors in a Mountain Ultramarathon. Int. J. Sports Med. 2017, 38, 819-826. [CrossRef]

3. Barnes, K.R.; Kilding, A.E. Running Economy: Measurement, Norms, and Determining Factors. Sports Med. Open 2015, 1. [CrossRef]

4. Ehrström, S.; Tartaruga, M.P.; Easthope, C.S.; Brisswalter, J.; Morin, J.-B.; Vercruyssen, F. Short Trail Running Race: Beyond the Classic Model for Endurance Running Performance. Med. Sci. Sports Exerc. 2018, 50, 580-588. [CrossRef]

5. Jones, A.M. A Five Year Physiological Case Study of an Olympic Runner. Br. J. Sports Med. 1998, 32, 39-43. [CrossRef]

6. Joyner, M.J. Modeling: Optimal Marathon Performance on the Basis of Physiological Factors. J. Appl. Physiol. 1991, 70, 683-687. [CrossRef]

7. McLaughlin, J.E.; Howley, E.T.; Bassett, D.R.; Thompson, D.L.; Fitzhugh, E.C. Test of the Classic Model for Predicting Endurance Running Performance. Med. Sci. Sports Exerc. 2010, 42, 991-997. [CrossRef]

8. Midgley, A.W.; Mc Naughton, L.R.; Wilkinson, M. The Relationship between the Lactate Turnpoint and the Time at VO2max during a Constant Velocity Run to Exhaustion. Int. J. Sports Med. 2006, 27, 278-282. [CrossRef]

9. Morgan, D.W.; Baldini, F.D.; Martin, P.E.; Kohrt, W.M. Ten Kilometer Performance and Predicted Velocity at VO2max among Well-Trained Male Runners. Med. Sci. Sports Exerc. 1989, 21, 78-83. [CrossRef]

10. Scheer, V.; Janssen, T.I.; Vieluf, S.; Heitkamp, H.-C. Predicting Trail-Running Performance with Laboratory Exercise Tests and Field-Based Results. Int. J. Sport. Physiol. Perform. 2019, 14, 130-133. [CrossRef]

11. Millet, G.P.; Millet, G.Y. Ultramarathon Is an Outstanding Model for the Study of Adaptive Responses to Extreme Load and Stress. BMC Med. 2012, 10, 77. [CrossRef]

12. Sharma, A.P.; Saunders, P.U.; Garvican-Lewis, L.A.; Clark, B.; Welvaert, M.; Gore, C.J.; Thompson, K.G. Improved Performance in National-Level Runners With Increased Training Load at 1600 and 1800 m. Int. J. Sports Physiol. Perform. 2019, 14, 286-295. [CrossRef]

13. Navalta, J.W.; Montes, J.; Bodell, N.G.; Salatto, R.W.; Manning, J.W.; DeBeliso, M. Concurrent Heart Rate Validity of Wearable Technology Devices during Trail Running. PLoS ONE 2020, 15, e0238569. [CrossRef]

14. Nasiri, S.; Khosravani, M.R. Progress and Challenges in Fabrication of Wearable Sensors for Health Monitoring. Sens. Actuators A Phys. 2020, 312, 112105. [CrossRef]

15. Sinnapolu, G.; Alawneh, S. Intelligent Wearable Heart Rate Sensor Implementation for In-Vehicle Infotainment and Assistance. Internet Things 2020, 12, 100277. [CrossRef]

16. Cerezuela-Espejo, V.; Hernández-Belmonte, A.; Courel-Ibáñez, J.; Conesa-Ros, E.; Mora-Rodríguez, R.; Pallarés, J.G. Are We Ready to Measure Running Power? Repeatability and Concurrent Validity of Five Commercial Technologies. Eur. J. Sport. Sci. 2020, 1-22. [CrossRef]

17. Paton, C.D.; Hopkins, W.G. Tests of Cycling Performance. Sports Med. 2001, 31, 489-496. [CrossRef]

18. Péronnet, F.; Thibault, G. Mathematical Analysis of Running Performance and World Running Records. J. Appl. Physiol. 1989, 67, 453-465. [CrossRef]

19. Navalta, J.W.; Montes, J.; Bodell, N.G.; Aguilar, C.D.; Radzak, K.; Manning, J.W.; DeBeliso, M. Reliability of Trail Walking and Running Tasks Using the Stryd Power Meter. Int. J. Sports Med. 2019, 40, 498-502. [CrossRef]

20. Shearer, L.; Hayden, N.; Lara, F.; Coppi, M.; Ogden, J.; Murr, S.; Sobolewski, E.; Hutchison, R. Reliability Between Running Power Meter Footpods During Trials Of Submaximal Running On Three Different Surfaces: 1839 Board \#100 May 31 3. Med. Sci. Sports Exerc. 2018, 50, 436. [CrossRef]

21. Easthope, C.S.; Nosaka, K.; Caillaud, C.; Vercruyssen, F.; Louis, J.; Brisswalter, J. Reproducibility of Performance and Fatigue in Trail Running. J. Sci. Med. Sport 2014, 17, 207-211. [CrossRef] [PubMed]

22. Imbach, F.; Candau, R.; Chailan, R.; Perrey, S. Validity of the Stryd Power Meter in Measuring Running Parameters at Submaximal Speeds. Sports 2020, 8, 103. [CrossRef]

23. Tartaruga, M.P.; Brisswalter, J.; Peyré-Tartaruga, L.A.; Avila, A.O.V.; Alberton, C.L.; Coertjens, M.; Cadore, E.L.; Tiggemann, C.L.; Silva, E.M.; Kruel, L.F.M. The Relationship between Running Economy and Biomechanical Variables in Distance Runners. Res. $Q$. Exerc. Sport 2012, 83, 367-375. [CrossRef] [PubMed]

24. García-Pinillos, F.; Roche-Seruendo, L.E.; Marcén-Cinca, N.; Marco-Contreras, L.A.; Latorre-Román, P.A. Absolute Reliability and Concurrent Validity of the Stryd System for the Assessment of Running Stride Kinematics at Different Velocities. J. Strength Cond. Res. 2018. [CrossRef] [PubMed]

25. Björklund, G.; Swarén, M.; Born, D.-P.; Stöggl, T. Biomechanical Adaptations and Performance Indicators in Short Trail Running. Front. Physiol. 2019, 10. [CrossRef]

26. Woan, G. The Cambridge Handbook of Physics Formulas; Cambridge University Press: Cambridge, UK, 2000.

27. Balducci, P.; Berthou, A. Les 100 Notions Clés de L'entrainement E de la Nutrition en Trail; Les petits guides du Trail Running \#1; Outdoor Editions: Lyon, France, 2019.

28. Winter, D.A. Biomechanics of Human Movement; Wiley \& Sons: New York, NY, USA, 1979. 
29. García-Pinillos, F.; Latorre-Román, P.Á.; Soto-Hermoso, V.M.; Párraga-Montilla, J.A.; Pantoja-Vallejo, A.; Ramírez-Campillo, R.; Roche-Seruendo, L.E. Agreement between the Spatiotemporal Gait Parameters from Two Different Wearable Devices and High-Speed Video Analysis. PLoS ONE 2019, 14, e222872. [CrossRef]

30. Esteve-Lanao, J.; Larumbe-Zabala, E.; Dabab, A.; Alcocer-Gamboa, A.; Ahumada, F. Running World Cross-Country Championships: A Unique Model for Pacing. Int. J. Sports Physiol. Perform. 2014, 9, 1000-1005. [CrossRef]

31. Minetti, A.E.; Ardigò, L.P.; Saibene, F. Mechanical Determinants of the Minimum Energy Cost of Gradient Running in Humans. J. Exp. Biol. 1994, 195, 211-225.

32. Gottschall, J.S.; Kram, R. Ground Reaction Forces during Downhill and Uphill Running. J. Biomech. 2005, 38, 445-452. [CrossRef]

33. Lussiana, T.; Hébert-Losier, K.; Millet, G.P.; Mourot, L. Biomechanical Changes during a 50-Minute Run in Different Footwear and on Various Slopes. J. Appl. Biomech. 2016, 32, 40-49. [CrossRef]

34. Telhan, G.; Franz, J.R.; Dicharry, J.; Wilder, R.P.; Riley, P.O.; Kerrigan, D.C. Lower Limb Joint Kinetics during Moderately Sloped Running. J. Athl. Train. 2010, 45, 16-21. [CrossRef]

35. Swanson, S.C.; Caldwell, G.E. An Integrated Biomechanical Analysis of High Speed Incline and Level Treadmill Running. Med. Sci. Sports Exerc. 2000, 32, 1146-1155. [CrossRef] [PubMed]

36. Townshend, A.D.; Worringham, C.J.; Stewart, I.B. Spontaneous Pacing during Overground Hill Running. Med. Sci. Sports Exerc. 2010, 42, 160-169. [CrossRef]

37. Kyröläinen, H.; Belli, A.; Komi, P.V. Biomechanical Factors Affecting Running Economy. Med. Sci. Sports Exerc. 2001, 33, 1330-1337. [CrossRef]

38. García-Pinillos, F.; García-Ramos, A.; Ramírez-Campillo, R.; Latorre-Román, P.Á.; Roche-Seruendo, L.E. How Do Spatiotemporal Parameters and Lower-Body Stiffness Change with Increased Running Velocity? A Comparison between Novice and Elite Level Runners. J. Hum. Kinet. 2019, 70, 25-38. [CrossRef] [PubMed]

39. Giandolini, M.; Horvais, N.; Rossi, J.; Millet, G.Y.; Morin, J.-B.; Samozino, P. Effects of the Foot Strike Pattern on Muscle Activity and Neuromuscular Fatigue in Downhill Trail Running. Scand J. Med. Sci. Sports 2017, 27, 809-819. [CrossRef] [PubMed] 